\title{
Somewhere in Northern Shaanxi Tourism Scenic Spot Design Scheme Comparison \\ Xiao Qiang Wu
}

(yanan university construction engineering school Shaanxi yan 'an 716000).

Email:nwwolf197724@163.com.

Keywords: Mountain slope ; Protection; Scheme comparison; Prevention and control measures

\begin{abstract}
: in view of the northern shaanxi somewhere scenic spots surrounding environment situation, through comparing two kinds of design of slope protection, which focuses on a more affordable slope protection project, planning and decision-making for similar areas to provide the related technical indicators, provide reasonable prevention measures and reference.
\end{abstract}

\section{Project summary}

Qiankun bay, according to the Yellow River scenic area overall planning "and" the meander of the Yellow River "master plan of national geological park, an oil company in the Yellow River bay tourism development, realize the regional tourism foreign reception capacity, local folk culture, with the Yellow River Qin Jin grand canyon bare rock as the carrier, enrich tourism products, promote the development of tourism products, according to the planning in the orderly development, and constantly improve the infrastructure of the scenic spot, gradually expand the content of sightseeing, to extend the time of tourists stranded, the scenic spot in the four seasons long green, three quarters of flowering, facilities, set sightseeing, leisure vacation, folk custom, flavor food as one of the largest tourism, leading role to achieve tourism development areas, increasing the income of the local national economy, solve part of the local people of employment, to improve their living standards, expand qiankun bay in shaanxi province and the country's popularity, attract more people to the tourism, promote the development of county economy, the construction of a harmonious society[1 6].

\section{The scenic spot design plan:}

Some slope protection scheme design unit: slope protection design concept to assume things around the scenic area of the Yellow River on the left bank slope for the sliding body, with anti-slide pile, anchor wire and soil measures to prevent the slope sliding plate structure, the pile length of $25.0 \mathrm{~m}$, embedded into the bedrock of $9.0 \mathrm{~m}$, the soil section plus $2 \mathrm{Vom} 15$ anchor cable, $35.0 \mathrm{~m}$ in length, along the eight-lane cliff elevation of $10.0 \mathrm{~m}$, graphic (1) are arranged on axis 1.0 $\mathrm{x} 1.5$ ten anti-slide pile, (2) set up $141 \mathrm{x}$ axis $7.05 \mathrm{~m}, 0.9 \mathrm{~m}$ anti-slide pile, the minimum $+/-0.00$ in the arrangement of the micromorphological $52200 \mathrm{~mm}$ diameter pile, the length of $16.0 \mathrm{~m}$, pile top have long penetration beam, slope 400 thick concrete site casting, all for the $\mathrm{C} 30$ concrete level ${ }^{[7,8]}$.

Revetment scheme defects: assume that landslides.The design idea of retaining wall with micro anti-slide pile shape against scientific principle, field investigation for the early stage of the design is not careful, caused by subjective inference. According to an engineering investigation institute issued in March 2012, the Yellow River qiankun bay scenic qiankun machine and qiankun bay area service area construction engineering geological disaster risk assessment report have clear conclusion has four:

(1) the project looks remarkably loess Liang Mao area landscape for the quaternary terraces and exposed bedrock group of yanchang formation mainly for paper fang, extend the set of sandstone and mudstone and quaternary upper pleistocene series eolian loess. Fault and fold in the area is not development, new tectonic movement is mainly characterized by intermittent uplift movement, 
species in geotechnical engineering is simple, the better engineering geological properties, human engineering activities on the geological environmental impact is small, complexity of geological environmental conditions of evaluation area, is a simple $\sim$ medium types, determine the level of project evaluation for level 3.

(2) the current situation of geologic disaster danger evaluation shows, found no geological disaster survey area, small risk present situation assessment.

Design thinking for the assessment report have qualitative stability of the slopes to landslide treatment, with scientific principles, must increase investment, extend the time limit for a project, have money to waste, reducing investment performance, etc. This section of highway and railway, also do not have large vehicles disturbance, scenic also impossible to build a big project, small peripheral environment influence on the slope, slope governance can unload and and ecological measures is given priority to, the management of engineering measures are complementary.

No important scenic areas, buildings and structures, few people and decentralization, strong seasonality, actual situation, the slope at the top of the geomorphic features of residual beam width $80 \sim 150 \mathrm{~m}$, the natural slope is too steep, the upper covering thickness is less than $20.0 \mathrm{~m}$, according to the slope engineering technical specifications "GB50330-2002" regulation, the slope safety level should be level 2 , should not be increased.

Slope governance should be given priority to with unloading and ecological measures, qiankun machine trailing edge of the scenic spot mountain ridge is wide, slope is relatively slow, covering layer of quaternary holocene respectively (Q4) tillage soil and quaternary pleistocene series (Q3) loess, paleosol and Triassic middle sandy shale argillaceous sandstone, no traces the ancient landslide, uninstall program can be used to eliminate the soil cliff fall of landslide hazard, which cut mountain, put slope, build order. Using artificial terrace slope is slower, planting trees grow grass, drainage, rainwater organized discharge, reduce the rain erosion on the slope surface and cutting, to achieve double effect of slope governance and beautify the environment.

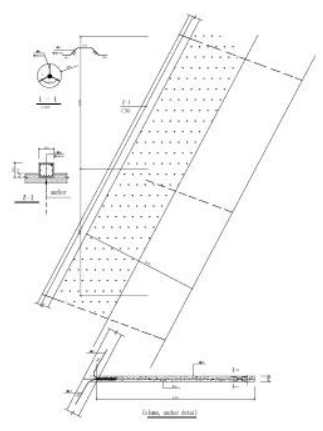

Figure. 1 lattice column, anchor detail

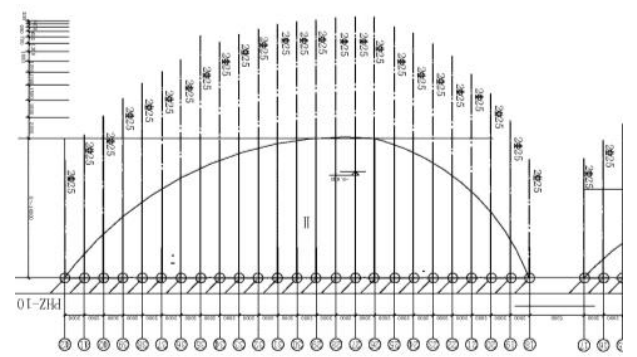

Figure. 3 "V" shaped gully slope protection pile layout Figure4 revetment pile reinforcement figure

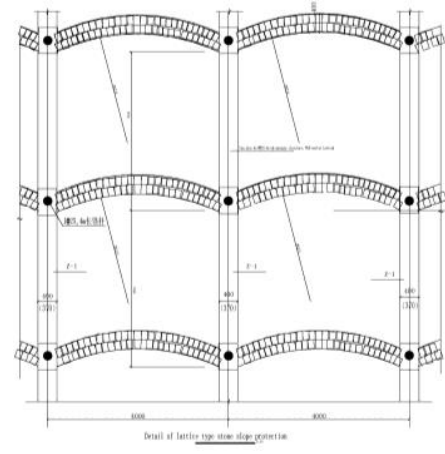

Figure. 2 stone slope protection detail

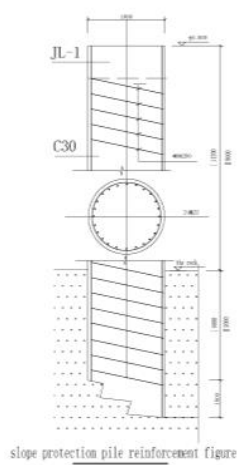




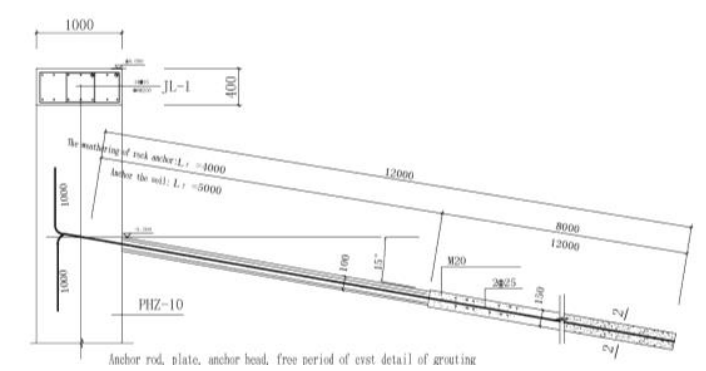

Figure. 5 plate, anchor bolt head, free package detail

Design change proposal. Supplementary investigation: (1) the tide table a bid began construction of scenic spots, along the mountain scenic area square with earthwork excavation is in full swing, bareness mountain cliffs, prospecting units can be directly on the slope surface acquisition pattern, send laboratory analysis to determine the relevant data, than artificial exploratory well energy and time, also need not use drilling machinery, investigation personnel can be directly to watch the soil structure and vertical joint distribution. Supplementary investigation conclusion more in line with the actual, more scientific and reasonable proposals ${ }^{[9,10]}$.

(2) the supplementary investigation report after coming out, design personnel according to the investigation report as the basis, make a scientific, reasonable and economic, security, slope protection scheme.

(3) slope protection engineering design for half experience and half theory, many practice will remain to be perfected, engineering experience rely on engineering measures also cannot completely eliminate the unsafe hidden trouble ${ }^{[7]}$.

\section{Economic analysis:}

A design unit design cost 3.07 million. Project content has anti-slide pile, micro shape of pile, soil retaining plate, anchor cable.

Cost 1.3 million after the change. Project content, anchor the lattice framework $1900 \mathrm{~m}, 140 \mathrm{~m}$ gravity retaining wall.

\section{Conclusion}

This project supporting the design of slope protection through detailed design and comparison, according to the soil and the surrounding topography and the surrounding site condition is different, use a variety of flexible revetment supporting technology, to ensure that the area safe and reliable, has obtained the good economic and social benefits. Therefore, in the mountain scenic area construction planning, especially in previous engineering investigation, should attach great importance to the investigation of geological disasters, take reasonable measures to prevent and control, on the one hand, want to be in planning work at the same time, strengthen the engineering geological conditions of the site survey, provides the prerequisite for planning and decision-making, prevent waste investment; On the other hand is to strengthen disaster regulation, to ensure the safety of the project.

\section{References:}

[1] Z.X. Li, Method and Its Application in Static Load Pile Test [J]. Architectural technology, 2000, $31(3): 157-159$.

[2] G.Q. Luo. Masonry Structure [M]. Changsha: hunan science and technology press, 1993.

[3] DZ/T 0219-2006, the Landslide Prevention and Control of Engineering Design and Construction Technical Specification $[S]$.

[4]GB50021-2001 [1], the Geotechnical Engineering Specification [S]. Beijing: China building industry press, 2009. 
[5] GB50007-2010), the Building Foundation Design Specification [S]. Beijing: China building industry press, 2011.

[6] GB50330-2010, building slope engineering specification [S]. Beijing: China building industry press, 2011.

[7]. The Finite Element Simulation and Stability Analysis of Slope Excavation [J]. Journal of rock mechanics and engineering, 2002, 21 (6) : 843-847.

[8] D.G. Zhang. Theory of Urban Positioning - sociological Theory Under the View of Sustainable Development Strategy [M]. Nanjing: southeast university press, 2008.

[9] DZ/T 0219-2006, the Landslide Prevention and Control of Engineering Design and Construction Technical Specification [S].

[10] Claire markus cooper, etc. Humanity places - urban open space design guide [M]. Sasaki, et al. Beijing: China building industry press, 2001. 